\title{
O CONCEITO LUGAR NA PERSPECTIVA DA GEOGRAFIA ESCOLAR
}

\begin{abstract}
Cristina Maria Costa Leite ${ }^{1}$
Resumo: A produção científica recente das linhas de pesquisa relacionadas aos processos de ensino/aprendizagem em Geografia atesta conquista de espaço acadêmico, profundidade nas abordagens teóricas e amplitude temática. Nesse contexto, e considerando-se as características inusitadas do atual momento histórico, onde se destaca o processo de globalização da economia e suas implicações na produção dos espaços, o conceito de Lugar emerge na Geografia Científica e Escolar com importância redimensionada. Assim, e no escopo dessa situação, o presente artigo objetiva analisar tal conceito em suas vertentes materialista e fenomenológica para, a partir daí, associá-lo à dimensão escolar. A perspectiva materialista histórica dialética é pautada pelas contribuições de Santos (1994) e Carlos (2007); a fenomenológica orienta-se por Oliveira (1977) e Tuan (1980). Desse modo, identificados como o conceito de Lugar é considerado nessas fundamentações filosóficas, analisa-se como ocorre em âmbito escolar. Conclui-se que, na perspectiva da Geografia Escolar, o conceito de Lugar é multiescalar e fundamental à construção/consolidação da noção de cidadania. Além disso, apresenta uma racionalidade particular, que no contexto das relações cotidianas de ensino-aprendizagem, especificamente no tocante às mediações necessárias à construção do conhecimento, articula as perspectivas materialista e fenomenológica, que se conjugam para conferir significação aos conteúdos abordados.
\end{abstract}

Palavras-chave: Geografia Escolar. Lugar. Materialismo Histórico Dialético. Fenomenologia.

\section{THE PLACE CONCEPT IN THE SCHOOL GEOGRAPHY PERSPECTIVE}

Abstract: The recent scientific results of the research lines related to the teaching / learning processes in Geography attests to the achievement of academic space, depth in theoretical approaches and thematic scope. In this context, and considering the unusual characteristics of the current historical moment, which highlights the process of globalization of the economy and its implications in the production of spaces, the concept of Place emerges in the Scientific and School Geography with importance in scale. Thus, in the scope of this situation, the present article aims at to analyze this concept in its materialist and phenomenological aspects and, from there, to associate it with the school dimension. The dialectical historical materialist perspective is based on the contributions of Santos (1994) and Carlos (2007); the phenomenological one is guided by Oliveira (1977) and Tuan (1980). Thus, identified the concept of Place is considered in these philosophical foundations, it is analyzed as it occurs in school scope. It is concluded that, from the perspective of School Geography, the concept of Place is multiscale and fundamental to the construction / consolidation of the notion of citizenship. In addition, it presents a particular rationality, which in the context of everyday teaching-learning relations,

\footnotetext{
${ }^{1}$ Geógrafa, Doutora em Educação, com Mestrado em Gestão Ambiental e Especialização em Gestão do Território e Sensoriamento Remoto. Professora efetiva da Universidade de Brasília, com atuação na Graduação em Pedagogia e na Pós-Graduação em Geografia. Coordena o grupo de pesquisa - Ensino, Aprendizagem e Formação de Professores em Geografia da Universidade de Brasília - GEAF/UnB. Email: criscostaleite@gmail.com
} 


\section{REVISTA ELETRÔNICA \\ DA GRADUAÇÃO/PÓS-GRADUAÇÃO EM EDUCAÇÃO UFG/REJ}

\section{ITINERPARIIUS REFLECTIONIS}

ISSN. 1807-9342

Volume 14, N. 2, 2018

specifically in relation to the mediations necessary for the construction of knowledge, articulates the materialist and phenomenological perspectives, which combine to give significance to the contents addressed.

Keywords: School Geography. Place. Dialectical Historical Materialism. Phenomenology.

\section{INTRODUÇÃO}

Os últimos anos atestaram significativo incremento às publicações referentes à Geografia Escolar, decorrente da consolidação da linha de pesquisa em ensino/aprendizagem em Geografia, em nível de graduação e pós-graduação, bem como da articulação dessas instâncias com rede de professores da escola básica. A obtenção de "espaço acadêmico, profundidade teórica e amplitude temática" (CAVALCANTI, 2010, p.5) foi resultado de um amplo processo, que se iniciou na década de 1990, conforme atesta essa autora:

Na década de 1990, no contexto sociopolítico, científico e educacional de crise e de ampliação dos referenciais interpretativos da realidade, as orientações para o trabalho docente com a Geografia foram se reconstruindo. Surgiram propostas alternativas, mais articuladas a orientações pedagógico-didáticas, definindo diferentes métodos para o ensino de Geografia. Com essas novas orientações, reafirmou-se o papel relevante da Geografia na formação das pessoas e reconheceu-se que mudanças relacionadas ao cotidiano espacial de uma sociedade globalizada, urbana, informacional, tecnológica requerem uma compreensão do espaço que inclua a subjetividade, o cotidiano, a multiescalaridade, a comunicação, as diferentes linguagens do mundo atual (CAVALCANTI, 2010, p.5).

Considerando-se as características inusitadas desse momento histórico, onde se destaca o processo de globalização da economia e suas implicações na produção dos espaços, o conceito de lugar emerge na Geografia Científica e Escolar com importância redimensionada. Assim, e no escopo dessa situação, o presente artigo objetiva analisar tal conceito em suas dimensões materialista e fenomenológica para, a partir daí, associálo à perspectiva escolar.

O lugar é um conceito cujos primórdios remetem à Antiguidade. $\mathrm{Na}$ Ciência Geográfica, constitui-se uma perspectiva analítica proveniente das filosofias de significado (fenomenologia, existencialismo, idealismo, hermenêutica), que se contrapõe à abordagem pautada no positivismo de Ratzel (1914), La Blache (1982), 


\section{REVISTA ELETRÔNICA \\ DA GRADUAÇÃO/PÓS-GRADUAÇÃOO EM EDUCAÇÃO}

UFG/REJ

\section{ITHEERAR IIS \\ REFLECTIONIS}

ISS N. 1807-9342

Volume 14, N. 2, 2018

Hettner (1977) e Reclus (1980). Nesse sentido, e a despeito de já ter estabelecido referências teóricas desde a década de 30, pelas contribuições da Geografia Cultural de Schluter (1920) e Sauer (1925), a concepção de lugar encontra no processo de ruptura com a fundamentação positivista, um terreno fértil para seu desenvolvimento.

Algumas das reflexões recentes na área da Geografia Humana enunciam o conceito de lugar, até mesmo por força dos processos que ocorrem em escala global, com rebatimento imediato em nível local. O conceito de lugar é, então, retomado e ressignificado ante a contemporaneidade. Nesse sentido, constata-se que esse conceito vem sendo utilizado, não somente, nas referências estabelecidas com base no materialismo histórico dialético, a Geografia Crítica, como também naquelas decorrentes da fundamentação fenomenológica, as Geografias Humanística, da Percepção e Cultural. Em ambas as fundamentações o lugar é considerado categoria de análise do pensamento geográfico e constitui-se um conceito fundante dessa investigação, conforme pode ser verificado nas sínteses que se seguem, elaboradas a partir das considerações de Santos (1994) e Carlos (2007), referentes ao materialismo, e Oliveira (1977) e Tuan (1980), para a fenomenologia. Assim, procurar-se-á identificar, a partir das visões desses autores, como o conceito de lugar é considerado nessas fundamentações filosóficas.

\section{O LUGAR NO MATERIALISMO HISTÓRICO DIALÉTICO}

$\mathrm{Na}$ perspectiva do materialismo o conceito de lugar é indissociável e decorrente do conceito de espaço geográfico. Esse é compreendido como uma produção social, um resultado, um produto do trabalho da sociedade em cada momento histórico. Esse espaço, que é produto social porque é produzido coletivamente pelo trabalho e histórico porque é decorrente de um dado período da história, apresenta-se como um trabalho materializado, acumulado a partir de uma série de gerações. Isso atesta que, não somente, esse espaço se produz com uma carga significativa de valores, que são diferenciados entre si pelos seus usos, como também que o processo de produzir/reproduzir desse espaço é um ato de apropriação. $O$ sentido do espaço produzido é, então, aquele marcado por modos de produção e, consequentemente, de apropriação. 


\section{REVISTA ELETRÔNICA \\ DA GRADUAÇÃO/PÓS-GRADUAÇÃO EM EDUCAÇÃO UFG/REJ}

\section{ITTERPARUIS REFLECTONIS}

ISSN. 1807-9342

Volume 14, N. 2, 2018

Nesse contexto, de produção social e histórica do espaço, os processos de produção e reprodução encontram-se plenamente articulados: a produção refere-se ao que é específico, enquanto a reprodução permite apreender a divisão do trabalho em seu movimento, pois considera a acumulação de capital através dos mecanismos de sua própria reprodução. $\mathrm{O}$ processo de reprodução está associado às condições de vida da sociedade e é determinado por elas: é o espaço que intervém na produção e organização do trabalho produtivo.

O espaço geográfico determina as relações de produção sendo, simultaneamente, produtor, produto e suporte das relações sociais. Por isso desempenha importante papel no processo de reprodução geral da sociedade, estabelecendo uma produção espacial que se manifesta em formas distintas de apropriação, utilização e ocupação de um determinado lugar. Tal diversidade, revelada pelo uso do espaço, expressa a divisão social e técnica do trabalho, que resulta numa morfologia espacial fragmentada e hierarquizada, decorrente da superposição de níveis econômicos e políticos, vinculadas a estratégias mundiais.

Desse modo, o espaço constitui-se lugar e meio de reprodução das relações de produção e engloba a produção do espaço em geral, atestando a divisão do trabalho em escala planetária. Para se tornar espaço, o mundo depende da interação entre o sistema de objetos (força produtiva) e o sistema de ações, (conjunto das relações sociais de produção). A interação desses dois sistemas é denominada de virtualidades (SANTOS, 1994). Assim, o mundo demanda virtualidades para constituir o espaço.

A produção do espaço ocorre no cotidiano, como forma de ocupação e uso do lugar num determinado tempo e expressa duas dimensões: a primeira diz respeito ao processo de mundialização da sociedade urbana como um todo, que estabelece um padrão único de urbanização, constituindo espaços urbanos homogêneos em escala mundial; a segunda refere-se à fragmentação do espaço e do indivíduo, que perde suas referências a cada momento. Tal perda é decorrente da redefinição constante dos usos de tempo e espaço que, simultaneamente, criam identidades e destroem as condições nas quais são Estados os componentes da memória coletiva.

Tais considerações sobre o espaço geográfico evidenciam que a concepção de lugar que emerge na perspectiva do materialismo histórico, constitui-se uma possibilidade: a compreensão da complexidade envolvida no processo de produção de 


\section{REVISTA ELETRÔNICA \\ DA GRADUAÇÃO/PÓS-GRADUAÇÃOO EM EDUCAÇÃO}

UFG/REJ

\section{ITHERARIIIS \\ REFLECTIONIS}

ISS N. 1807-9342

Volume 14, N. 2, 2018

um espaço mundial. Isso porque o lugar se produz na articulação contraditória entre o mundial que se anuncia e a especificidade histórica do particular.

Como a produção do espaço é um processo que se constitui em escala mundial e essa dimensão não é concreta, a despeito de se estabelecer concretamente no território, o lugar se apresenta como a via onde a abstração da produção do espaço se materializa:

O lugar permitiria entender a produção do espaço atual uma vez que aponta a perspectiva de se pensar seu processo de mundialização. $\mathrm{O}$ lugar abre a perspectiva para se pensar o viver e o habitar, o uso e o consumo, os processos de apropriação do espaço. Ao mesmo tempo, posto que preenchido por múltiplas coações, expõe as pressões que se exercem em todos os níveis (CARLOS, 2007, p.52).

Importante destacar, nesse contexto, que existe uma diferença entre lugar e local: o primeiro refere-se ao ponto de articulação entre o mundial que se anuncia e a especificidade histórica do particular. É onde se vive, onde o cotidiano se realiza e por isso, expressa o caráter mundial. Daí sua importância, ou seja, para compreender o processo de produção do espaço, que é mundial, basta analisar o lugar que é onde aquela produção toma forma concreta, se materializa, se reinventa e confere novos significados a esse lugar. O local, ao contrário, diz respeito à especificidade concreta, é o momento; constitui-se apenas uma etapa do processo, uma variável a mais.

Santos (1994) ressalta que a discussão sobre o conceito de lugar envolve duas perspectivas, a saber: o lugar visto de fora e o visto de dentro. O primeiro a partir de sua redefinição, resultado do acontecer histórico; o segundo é o que implicaria a necessidade de redefinir seu sentido. Assim, define o lugar por meio de suas densidades técnica, informacional, comunicacional e normativa. Nesse sentido, a densidade técnica se refere ao tipo de técnica que está presente na configuração atual do território; a informacional é aquela que chega ao território tecnicamente estabelecido; a comunicacional diz respeito aos processos de interação entre as pessoas; o normativo é a regulação e refere-se ao próprio papel das normas.

Carlos (2007) acrescenta a essas densidades a dimensão temporal, que diz respeito ao tempo de cada lugar, que pode ser visto por meio de um evento tanto no presente quanto no passado. Essa temporalidade, então, expressa a dimensão da história, que entra e se realiza no cotidiano. São essas densidades que configuram o território 


\section{REVISTA ELETRÔNICA \\ DA GRADUAÇÃO/PÓS-GRADUAÇÃO EM EDUCAÇÃO}

UFG/REJ

\section{ITHEERAPIIIS \\ REFLECTIONIS}

ISS N. 1807-9342

Volume 14, N. 2, 2018

como uma malha, que conferem ao lugar suas características intrínsecas. Assim, olhar o lugar apresenta duas perspectivas diferenciadas e complementares: a primeira é aquela externa, de quem vê o lugar de fora, como um recorte no espaço, expressando redefinição, resultado do acontecer histórico. O segundo refere-se à perspectiva de quem está dentro do lugar e por isso, apresenta a necessidade de redefinição de seu sentido.

\section{O LUGAR NA FENOMENOLOGIA}

O aporte da fenomenologia na Ciência Geográfica ocorre muito antes da renovação paradigmática da década de 1970. É na obra de Sauer (1925), que se estabelece o início de uma postura diferenciada para a consideração do espaço geográfico, uma vez que se objetiva traduzir os significados em busca da percepção e da visão cultural relativa ao conceito de paisagem. É a partir de sua produção, então, que a subjetividade passa a ser considerada nas relações entre o homem e seu espaço. Nesse sentido, e de acordo com Sasaki (2010), os anos 40 e 50 dão continuidade à trajetória de incorporação da subjetividade nos estudos geográficos, por meio das obras de Wright (1966) e Lowenthal (1961). O primeiro produz a Geosofia, que se constitui uma modalidade de estudo sobre a realidade, por meio de obras não científicas e da imaginação, como fundamento para o conhecimento da própria realidade; o segundo, que consolida os estudos humanísticos e cognitivos sobre a percepção, propõe que a compreensão da realidade deve considerar as distorções de interpretação dos sujeitos, que são influenciados pelos sentimentos, tempo histórico e o compartilhamento do real pelo seu próprio grupo social.

É com Tuan (1980, 1983, 1985), que a fenomenologia chega à Geografia Brasileira. Sua obra apresenta uma concepção influenciada pela fenomenologia de Heidegger e Merlau-Ponty (SASAKI, 2010) e Dardel (MARANDOLA; GRATÃO, 2003), na qual se afirma o interesse nas relações entre conhecimento e existência e a necessidade de não objetivação da realidade. Nesse contexto, espaço e lugar constituemse categorias fundamentais à análise de Tuan, que procura explicá-las e diferenciá-las ao longo de sua produção: considera que o espaço é um símbolo comum de liberdade no mundo ocidental, que se transforma em lugar à medida que adquire definição e 


\section{REVISTA ELETRÔNICA}

DA GRADUAÇÃO/PÓS-GRADUAÇÃO EM EDUCAÇÃo

UFG/REJ

\section{ITHEPApIIS REFLECTIONIS}

ISS N. 1807-9342

Volume 14, N. 2, 2018

significado. Importante ressaltar que é por meio da produção de Tuan, que o lugar deixa de ter uma conotação espacial e agrega a experiência vivida dos sujeitos como forma de configuração da realidade. O lugar é, então, um espaço fechado e humanizado; é uma classe especial de objeto; é uma concreção de valor; é um objeto no qual se pode morar.

Tuan emprega o termo Topofilia, em livro do mesmo nome (1980), para representar um traço de afetividade humana ao lugar. Nesse sentido, ter amor por algum lugar evidencia um sentimento topofilico. Nesse processo, considera e valoriza a experiência, como fator fundamental para o conhecimento do espaço. Assim, espaço se constitui lugar, quando é produto da experiência humana, que produz significados, os quais são construídos por referências afetivas desenvolvidas ao longo da vida, por meio da convivência. A experiência, nessa perspectiva, expressa a capacidade de aprender a partir da própria vivência; significa aprender, atuar sobre o dado e criar a partir dele. O lugar, então, atinge a realidade concreta quando a experiência do sujeito com ele é total. A realidade passível de conhecimento é aquela que é um constructo da experiência, uma criação de sentimento e pensamento. Assim, o conteúdo dos lugares é produzido pela consciência humana e por sua relação subjetiva com as coisas e com os demais seres humanos com os quais se relaciona. Constitui-se, então, em localização, em um artefato único, repleto de significados individuais e coletivos.

De acordo com Marandola e Gratão (2003) as bases da Geografia Humanista no Brasil foram estabelecidas pela UNESP de Rio Claro-SP, principal núcleo irradiador dos estudos de percepção ambiental e considerados, até os anos 90, o único esforço de difusão desta linha de investigação no país. Nesse contexto, é inconteste a importância de Oliveira (1977), que não somente traduz e difunde as obras de Tuan (1980, 1983, 1985), como também apresenta expressiva produção pautada pelos fenômenos imateriais.

Para Oliveira (1977), uma das grandes contribuições da Geografia Humanista diz respeito à consideração de problemas filosóficos, por meio da categoria de lugar, como foco da afetividade e relação com o ambiente. Para ela, "no lugar se dá a experiência; nele Tuan assenta sua obra e, é nesta noção que a fenomenologia mais contribuiu, até agora, aos estudos geográficos" (apud MARANGOLA; GRATÃO, 2003, p.15). Nesse sentido, considera que esta Geografia multifacetada pode humanizar a leitura da economia, da física, entre outras, na intenção de buscar uma integração 


\section{REVISTA ELETRÔNICA \\ DA GRADUAÇÃO/PÓS-GRADUAÇÃOO EM EDUCAÇÃO}

UFG/REJ

\section{ITHEERAPIIIS \\ REFLECTIONIS}

ISS N. 1807-9342

Volume 14, N. 2, 2018

homem ambiente e a valorização das paisagens e lugares. Além disso, identifica o olhar afetivo como uma tendência, num contexto de mundo marcado por várias globalizações, que repercutem na configuração das identidades.

A Geografia Humanística considera a valorização do ser humano e nesse contexto revaloriza os conceitos de paisagem, lugar e região, destacando a existência dos sujeitos e de seu sentimento de pertencimento a um dado espaço. Nessa perspectiva, o lugar assume uma personalidade, que se manifesta na história de cada sujeito, constituindo-se realidade na consciência individual, a partir do relacionamento com o espaço. O lugar é um núcleo de significados imprescindível para a configuração da identidade individual de cada sujeito, membro de uma determinada comunidade. Assim, é possível afirmar que conceito de lugar passa a ser compreendido como uma categoria da Geografia, que transcende a delimitação espacial de uma porção de terra, que está contemplada numa dimensão subjetiva das mentes, memórias e histórias de vida, articuladas por uma relação emocional entre sujeitos. Essa corrente teórica demonstrou a importância da valorização do recorte espacial lugar, enquanto um espaço no qual as ideias, sentimentos espaciais e emoções dos sujeitos que o compartilham são considerados. Portanto,

o lugar não é um mero objeto, pois se constitui objeto para um sujeito; por isso um é centro de significados, intenções ou valores sentidos ou percebidos; um foco de ligação emocional ou sentimental; uma localidade de significância sentida ou percebida (SASAKI, 2010, p.119).

\section{O LUGAR NA GEOGRAFIA ESCOLAR CONTEMPORÂNEA}

As considerações efetuadas até o momento atestam que o lugar se constitui uma categoria de análise do espaço geográfico, não somente na perspectiva do materialismo histórico dialético, como também na fenomenologia. Em ambos representa a concretude do espaço, seja ele socialmente produzido, e aí atestando significados coletivos, ou único e singular perante o indivíduo, expressando significados pessoais. Em qualquer um desses casos, a cultura constitui-se um ponto de convergência, na medida em que estabelece referenciais coletivos ou pessoais e, por conseguinte, identitários. Entretanto, a análise dessa questão implica numa reflexão sobre os fundamentos epistemológicos e metodológicos da Geografia aplicados à escolarização, notadamente no que se refere à 


\section{REVISTA ELETRÔNICA \\ DA GRADUAÇÃO/PÓS-GRADUAÇÃOO EM EDUCAÇÃO}

UFG/REJ

\section{ITHERARIIIS REFLCTIONIS}

ISS N. 1807-9342

Volume 14, N. 2, 2018

constituição do saber geográfico, por meio do estudo do lugar e sua importância relativa ao processo de construção da identidade.

Considerando-se que o processo de iniciação escolar apresenta o conteúdo das ciências sociais como pano de fundo, estudar Geografia significa efetuar a leitura de mundo e construir a cidadania. Para isso incorpora-se o estudo do território objetivado à compreensão das relações que se estabelecem entre as pessoas, estruturadas num determinado tempo e espaço, constituindo uma cultura que pode estar, ou não, associada ao sujeito. Na escola, o período dos anos iniciais de escolarização corresponde àquele em que são construídos os conceitos básicos da área e que são fundamentais para a vida: são os conceitos sobre grupo/espaço/tempo que permitem responder as questões relativas à identidade (quem sou eu), ao reconhecimento da própria história (onde vivo), à identificação do espaço e às condições de produção material (como vivo), às condições de vida em sociedade e o pertencimento ao mundo (com quem vivo). O entendimento desses conceitos, que fornece elementos fundamentais à formulação de respostas àquelas questões, pode ser viabilizado por meio de atividades que estejam assentadas na realidade concreta dos estudantes e num espaço e tempo objetivamente definido.

Nesse contexto, o estudo do lugar constitui-se um conteúdo significativo para este período escolar, pois confere concretude ao lugar onde vive o estudante, ao delimitar um determinado tempo e espaço e, por conseguinte, permitir a análise de todos os aspectos da complexidade de uma determinada localidade. Assim, os elementos que expressam as condições sociais, econômicas, políticas do nosso mundo, tornam-se concretas, por estarem próximos ao estudante. Por isso tornam-se decodificáveis, adquirem sentido, permitem constatações, comparações, deduções, conclusões, por conter elementos simbólicos já conhecidos. Desse modo, o conhecimento da realidade consiste no processo de reconhecimento do que existe no lugar, com as devidas explicações para o que acontece e a análise crítica de como se dispõem as coisas. Ao final o aluno poderá se

reconhecer como cidadão que tem direitos e deveres ao pertencer à sociedade, e nela a diversos grupos sociais, que tem uma história construída por todos, que têm um tempo acontecido com diversos fatos importantes para si e para o conjunto da sociedade, e que vive 


\section{REVISTA ELETRÔNICA}

DA GRADUAÇÃO/PÓS-GRADUAÇÃOO EM EDUCAÇÃO UFG/REJ

\section{ITHERARIIIS \\ REFLCTIONIS}

ISS N. 1807-9342

Volume 14, N. 2, 2018

num espaço que é construído cotidianamente a partir do trabalho dos homens que ali vivem (CALLAI, 2000, p.89).

Importante ressaltar que essa perspectiva de análise não é linear, pois o conhecimento da realidade, por meio do lugar, pressupõe a incorporação da própria dinâmica de desenvolvimento do local, vislumbrando-a como um todo. A compreensão dessa dinâmica, na perspectiva do lugar, refere-se à identificação dos processos que resultam na construção do espaço, ao entendimento de como ocorrem as relações de poder, as relações entre as pessoas e à percepção do que é significativo para o aluno no contexto de sua formação. Então, estudar o lugar é uma possibilidade de apreensão concreta da organização do espaço, na medida em que a influência e/ou interferência dos vários segmentos da sociedade, dos interesses político-econômicos são passíveis de constatação, em confronto, inclusive, com interesses locais e da população que ali vive. Nessa dialética consolida-se a noção de identidade e evidencia-se a perspectiva materialista no conceito de lugar.

Considera-se que o estudo do lugar é importante porque se constitui uma possibilidade efetiva de conhecimento da realidade, posicionamento pessoal e coletivo e uma das bases para a construção de identificações e de cidadania. Por essa via, a compreensão do que ocorre no local vivido e conhecido possibilita o estabelecimento de parâmetros, através dos quais as suas e as outras realidades serão conhecidas e interpretadas. Considerando-se que em nível local materializam-se todas as relações que são produzidas em escala global, pode-se afirmar que o local ainda possibilita uma forma de compreensão de uma realidade que resiste e extrapola os limites do lugar. $\mathrm{O}$ mundo, então, torna-se passível de decodificação por meio do concreto que existe no local e nessa dialética constrúmo-nos a nós e o nosso coletivo. Compreender o local é compreender o mundo, pois as relações que produzem o espaço local são as mesmas que produzem os demais espaços, diferenciando-se pela escala, especificidades sócioculturais e modos de integração/exclusão ao contexto global. Portanto,

estudar e compreender o lugar em Geografia significa compreender o que acontece no espaço onde se vive para além de suas condições culturais e humanas (...)permite ao sujeito conhecer sua história e conseguir entender as coisas que ali acontecem (CALLAI, 2000, p.84). 


\section{REVISTA ELETRÔNICA \\ DA GRADUAÇÃO/PÓS-GRADUAÇÃOO EM EDUCAÇÃO}

UFG/REJ

\section{ITEPAP||S \\ REFLECTIONIS}

ISS N. 1807-9342

Volume 14, N. 2, 2018

Tal processo, de compreensão da realidade, inclusive global, por meio das relações concretas que se materializam em nível local, não é uma questão simples. Ao contrário, é complexa na medida em que supera uma lógica linear, pois a dialética da vida não apresenta esse formato. É complexa por estar permanentemente em processo de construção e num contexto de idas e vindas inter-relacionados, de construção/reconstrução/desconstrução de significados, que mediam não só o entendimento da realidade, como também as referências de cultura, identidade e paisagem, numa dinâmica muito veloz e, cada vez mais, articulada com um contexto global. Assim, a compreensão da realidade constitui-se, também, um confronto cotidiano com o sentido de pertencimento e, por conseguinte, de identificação com um determinado espaço, cultura, território. Quando se conhece o lugar vivido, nessa perspectiva, constrói-se um aprofundamento da compreensão do que ocorre aí, para além daí. Nesse processo de desvelamento, são criadas e constituídas identificações, permanentes ou intermitentes, locais ou globais, que imputam ao indivíduo, no caso o estudante, o reconhecimento de sua posição de sujeito no contexto da produção da vida em sociedade. Tal fato é condição para o entendimento da noção de cidadania.

\section{CONSIDERAÇÕES FINAIS}

As considerações efetuadas até o momento justificam a defesa do estudo do Lugar, como via de formação do indivíduo a partir do ensino de Geografia. Essa função, relevante no processo de escolarização, adquire maior importância por estar vinculada à formação da cidadania. Assume-se que formar o cidadão no contexto da escolarização, significa dar condições ao aluno de reconhecer-se como um sujeito que tem história, que tem um conhecimento prévio do mundo e que é capaz de construir seu conhecimento; significa compreender o espaço como resultado da vida e do se perceber parte deste processo. Ao se trabalhar o lugar do aluno no ensino de Geografia se está, deliberadamente, fazendo uma opção política, que pretende fazer com que o aluno se situe no espaço onde vive e o compreenda como um processo em que a sociedade, a qual ele integra, o constrói. Por isso esse ensino não é neutro. O fundamental, então, é conhecer a realidade em que se vive, no sentido de ir além de identificar o que existe e de buscar explicações sobre os processos que desencadeiam a própria realidade.

$\mathrm{O}$ estudo do lugar constitui-se, então, o conteúdo que serve para ser trabalhado 


\section{REVISTA ELETRÔNICA \\ DA GRADUAÇÃO/PÓS-GRADUAÇÃO EM EDUCAÇÃO UFG/REJ}

\section{ITTEERARUIS REFLECTONIS}

ISSN. 1807-9342

Volume 14, N. 2, 2018

como instrumento de uma base necessária a vida do aluno, a partir da sistematização das aprendizagens realizadas, e da construção de uma base referencial para aprendizagens futuras. Constitui-se num processo que envolve dois movimentos e um conteúdo: por ser o meio em que o aluno vive,

permite que se realizem, simultaneamente, a sistematização e as bases para trabalhar com outras realidades mais distantes, com fenômenos que exigem maiores generalizações e maior nível de abstração (CALLAI, 2005, p.79).

Para isso, então, destaca-se o papel do professor. Seu trabalho é de mediação, notadamente no que se refere ao processo de apropriação dos elementos da realidade próxima do estudante, a do lugar. Isso significa que o professor assume a responsabilidade de conhecer o lugar dos alunos, a localidade onde se situa a escola, sua história de constituição e suas características intrínsecas, para poder dialogar, identificar saberes, construir conhecimentos numa abordagem dialógica. Tal responsabilidade, de conhecer o lugar dos alunos à priori, constitui-se importante ferramenta de mediação e apresenta uma relação direta com a própria agencialidade do professor, pois são seus Estados intencionais (crenças, desejos e emoções) que influenciam o modo pelo qual ele pode atuar sobre o mundo (BRUNER, 1986).

No que se refere às questões de ensino-aprendizagem em Geografia e suas relações intrínsecas com os processos identitários, o conceito de lugar apresenta-se como multiescalar, pois transita de um extremo ao outro no território e até no planeta, assumindo a identidade de bairro, cidade, Estado, região, país, continente, num ir e vir constante, para buscar referências concretas que possibilitem a transposição didática, a formulação de conceitos, o estabelecimento de referenciais identitários. Nessa perspectiva, supera a dimensão tempo/espaço por possibilitar o trânsito em diferentes tempos e espaços e então, aportar indícios de identidade. Como elemento de mediação no processo de construção de conceitos, constitui-se em exemplo de uma situação específica do lugar e/ou de algo do lugar que possibilite uma generalização. Por isso expressa o que está sendo negociado em termos das interações necessárias ao processo de construção coletiva do conhecimento.

\section{REFERÊNCIAS}




\section{REVISTA ELETRÔNICA \\ DA GRADUAÇÃO/PÓS-GRADUAÇÃO EM EDUCAÇÃO UFG/REJ}

\section{ITINEPARIUS REFLECTONIS}

ISS N. 1807-9342

Volume 14, N. 2, 2018

BRUNER, Jerome. A Cultura da Educação. Tradução Marcos Domingues. Porto Alegre: Artmed, 2001.

GARCIA RAMON, M. D. Hogar, campo de movimento y sentido del lugar. In: GARCIA RAMON, M. D. Teoria y método em La Geografia humana anglosajona. Barcelona: Ariel, 1985, p.227-241.

CALLAI, Helena Copetti. Estudar o lugar para compreender o mundo. In: CASTROGIOVANNI, Antônio Carlos (org.). Ensino de Geografia: Práticas e Textualizações no Cotidiano. Porto Alegre/RS: Ed. Mediação, 2000, p.83-134.

. A Geografia e a escola: muda a Geografia? Muda o ensino? In:

Terra Livre. São Paulo: n. 16, 2001, p. 133-152.

Aprendendo a ler o mundo: a Geografia nos anos iniciais do Ensino Fundamental. Campinas: Cad. Cedes, v. 25, n. 66, p. 227-247, maio-ago. 2005. Disponível em http $/ /$ www.cedes.unicamp.br Acesso em: 005.07.2011.

CARLOS, Ana Fani Alessandri. O lugar no/do mundo. FFLCH. São Paulo: 2007. 85p. Disponivel em: http://www.fflch.usp.br/dg/gesp.Acesso em 22 abr. 2011.

CAVALCANTI, Lana de Souza. A geografia e a realidade escolar contemporânea: avanços, caminhos, alternativas. Anais do I Seminário Nacional: Currículo em Movimento - Perspectivas Atuais. Belo Horizonte, 2010. Disponível em: http://portal.mec.gov.br/docman/dezembro-2010-pdf/7167-3-3-geografia-realidadeescolar-lana-souza/file < Acesso em 28.02.2018.

HETTNER, Alfred. La Sistemática de La Geografia, Geografia General y Geografia Regional. Murcia: Didática Geográfica, n.1, maio 1977, p.31-36.

A Geografia como Ciência Corológica da Superficie Terrestre (1927). Rio de Janeiro: UFFF, Coleção Nossos Clássicos, 2012. Disponível em: www.uff.br/geographia/ojs/index.php/geographia/article/.../318 Acesso em 03.03.2012.

HOLZER, W. O lugar na Geografia humanista. Revista Território, Rio de Janeiro, v.4, n. 7, p. 67-78, jul.-dez. 1999.

HUSSERL, Edmund. Meditações cartesianas: introdução à fenomenologia. São Paulo: Madras, 2001.

LA BLACHE, Paul Vidal de. Principes de Géographie Humaine. Disponível em: http:/www.dominiopublico.gov.br/download/texto/ga000917.pdf. Acesso em 03.02.2012.

As características próprias da Geografia. In: CHRISTOFOLLETI, Antônio (Org). Perspectivas da Geografia. São Paulo: Difel, 1982, p.37-47. 


\section{REVISTA ELETRÔNICA \\ DA GRADUAÇÃO/PÓS-GRADUAÇÃO EM EDUCAÇÃO}

UFG/REJ

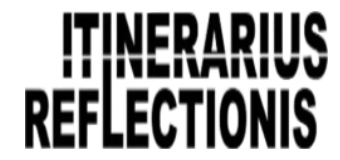

ISS N. 1807-9342

Volume 14, N. 2, 2018

LEITE, Cristina Maria Costa. O Lugar e a Construção da Identidade: os significados construídos por professores de Geografia do Ensino Fundamental. Tese de Doutorado. Universidade de Brasília, Faculdade de Educação, Programa de Pós-Graduação em Educação, 2012.

Educação no contexto contemporâneo: as possibilidades do Lugar. In: V Colóquio Internacional Educação e Contemporaneidade, 2011, Aracaju. Eixo Temático 5 - Educação e Ensino de Ciências Humanas e Sociais. Aracaju: Universidade Federal de Sergipe, 2011, p.1-12.

Geografia no Ensino Fundamental.Coleção Espaço e Geografia, Brasília: Universidade de Brasília/ Departamento de Geografia v.5, n. 2. Gestão Urbana e Regional. 2002.

LEITE, Cristina Maria Costa \& BARBATO, Silviane Bonacorsi. Reflexões Sobre a Construção do Conceito de Lugar na Escola Contemporânea. Brasília: Coleção Espaço \& Geografia, Vol.14, No 2, 1:31, 2011.

LOWENTHAL, David. Geography, Experience and imagination: towards a geographical epistemology.In: Annals of Association of American Geographers. New York/USA: Vol.51, n.3, p. 241-260, set. 1961.

MARANDOLA JR, Eduardo e GRATÃO, Lúcia Helena B. Do sonho a memória: Lívia de Oliveira e a Geografia Humanista no Brasil. Geografia. Revista do Departamento de Geociências, Londrina, Universidade Estadual de Londrina, v.12, n. 2, jul-dez. 2003. Disponível em http $/ /$ www.uel.br/revistas/uel/index.php/Geografia. Acesso em: $12 \mathrm{dez}$. 2011.

MERLEAU-PONTY, Maurice. Fenomenologia da percepção. São Paulo: Martins Fontes, 2a ed., 1999.

OLIVEIRA, Lívia. Contribuição dos estudos cognitivos à percepção geográfica. Geografia, Rio Claro, v.2, n.3, p.61-72, abr. 1977.

Percepção da paisagem geográfica: Piaget, Gibson e Tuan.

Geografia, Rio Claro, v.25, n.2, p.5-22, 2000.

. Estudo Metodológico e Cognitivo do mapa. In: ALMEIDA, Rosângela D. De (O); Cartografia Escolar; São Paulo: Ed. Contexto, 2007, p.15.

OLIVEIRA, Lívia \& XAVIER, Herbe. A percepção e a representação do espaço geográfico. Revista Pedagógica, v.54, 1991.

RATZEL, Friedrich. Geografia dell'uomo (AntropoGeografia). Principi d'aplicazione della scienza geográfica alla storia. Turin: Fratelli Boca Editori, 1914.

RECLUS, Elisée. La Geografia al servicio de la vida (Antologia). Barcelona: Coletivo de 


\section{REVISTA ELETRÔNICA \\ DA GRADUAÇÃO/PÓS-GRADUAÇÃO EM EDUCAÇÃO \\ UFG/REJ}

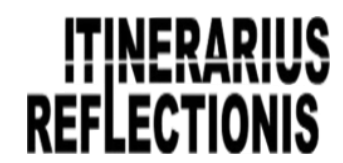

ISS N. 1807-9342

Volume 14, N. 2, 2018

Geógrafos, $7^{\mathrm{a}} \mathrm{Ed}, 1980$.

RELPH, Edward C. As bases fenomenológicas da Geografia. Revista Geografia, v. 4, n.7, p.1-25, abr. 1979.

SANTOS, Milton. Técnica, Espaço, Tempo: Globalização e meio técnico-científico informacional. São Paulo: Hucitec, 1994.

Da totalidade ao Lugar. São Paulo: Edusp, 1996.

SANTOS, Milton; SOUZA, Maria (org.). O espaço social numa perspectiva interdisciplinar. In: SANTOS, Milton; SOUZA, Maria (org.). O espaço interdisciplinar. São Paulo: Nobel, 1986, p.65-85.

SANTOS, Milton et al (orgs.). Fim de século e globalização. São Paulo: Hucitec ANPUR, 1993.

ANPUR, 1994. Território, globalização e fragmentação. São Paulo: Hucitec-

SASAKI, Karen. A contribuição da Geografia Humanística para a compreensão do conceito de Identidade de Lugar. Revista de Desenvolvimento Econômico-RDE, Salvador, Ano XIII, n. 22, p.112-120, dez. 2010.

SAUER, Carl O. The morphology of landscape. California : University of California Publications in Geography 2, 1925, p.19-54. Disponível em: http:/www.colorado.edu/geography/giw/sauer-co/sauer-co.html Acesso em 04.02.2012.

Hacia uma Geografia histórica. Discurso a la Associación Norteamericana de Geógrafos. Baton Rouge, Louisiana: 1940. Disponível em: www.colorado.edu/geography. Acesso em 02.02.2012.

SCHLÜTER, Otto. Über Inhalt und Aufgaben der Geographie. In: Erziehung und Bildung. Wissenschaftliche Beilage der Preussischen Lehrerzeitung 1, No. 10, 1920, p. 73-77.

TUAN, Yi-Fu. Topofilia: um estudo da percepção, atitudes e valores do meio ambiente. São Paulo: Difel, 1980.

.Espaço e lugar. São Paulo: Difel, 1983.

.Geografia Humanística. In: CHRISTOFOLETTI, Antonio (org.)

Perspectivas da Geografia. São Paulo: Difel, 1985. p.143-164.

WRIGHT, John Kirtland. Human Nature in Geography: Fourteen Papers, 1925-1965.

Cambridge, Harvard University Press, 1966. 